\title{
Criação e mudanças na estrutura do Ministério do Esporte do Brasil: tensões nas definições de espaços
}

CDD. 20.ed. 796.06

http://dx.doi.org/10.1590/1807-55092015000200217

\author{
Fernando Augusto STAREPRAVO* \\ Fernando Marinho MEZZADRI** \\ Wanderley MARCHI JUNIOR ${ }^{* *}$
}

*Centro de Ciências da Saúde, Universidade

Estadual de Maringá.

** Setor de Ciências

Biológicas, Universida-

de Federal do Paraná.

\section{Resumo}

0 presente artigo busca resgatar o processo de criação do Ministério do Esporte do Brasil e discutir alguns aspectos conflituosos da dimensão "politics" presentes em tal "policy cycle", que podem estar relacionados à reformulação efetivada por meio do recente Decreto Federal n. 7.529/2011. Para tanto, recorremos às entrevistas semi-estruturadas a agentes gestores do Ministério do Esporte. Sustentamos especialmente que a criação da Secretaria Nacional de Esporte, Educação, Lazer e Inclusão Social é reflexo tardio de algumas tensões envolvendo agentes de dois partidos distintos que estiveram desde 2003 (ano de criação do Ministério) envolvidos na administração do Ministério do Esporte.

Palavras-chave: Ministério do Esporte; Esporte; Políticas públicas; Arena política.

\section{Introdução}

A recente iniciativa do governo brasileiro em reformular a estrutura do Ministério do Esporte, através do Decreto $7.529 / 2011^{1 a}$, nos motivou a construir o presente artigo, a partir de parte de nossa tese de doutorado, que discutiu as relaçóes entre os subcampos político/burocrático ${ }^{b}$ e científico/acadêmico ${ }^{c}$ das políticas públicas de esporte e lazer no Brasil ${ }^{2}$.

Temos como presunção que a supracitada reformulação é reflexo tardio de algumas tensões envolvendo agentes de dois partidos distintos que estiveram desde 2003 (ano de criação do Ministério) envolvidos na administração do Ministério do Esporte, a saber, Partido Comunista do Brasil (PCdoB) e Partido dos Trabalhadores (PT).

Buscamos mais especificamente resgatar o processo de criaçáo do Ministério do Esporte e discutir alguns aspectos conflituosos da dimensão "politics" presentes em tal "policy cycle"e que podem estar relacionados à reformulação efetivada por meio do Decreto $7.529 / 2011^{1}$.

Tal empreitada se justifica, dentre outros motivos, pela escassez de trabalhos na área de políticas públicas de esporte e lazer que tratem da dimensão arena política no Brasil ${ }^{3}$.

\section{Método}

A metodologia da pesquisa considerou procedimentos diretos, através de entrevistas semi-estruturadas a agentes gestores do Ministério do Esporte presentes durante o processo de criação e implementação de tal pasta, que ocuparam cargos de segundo e terceiro escalâo na estrutura administrativa do Ministério. A escolha dos sujeitos foi intencional e considerou como critério o trânsito dos agentes na intersecção dos subcampos científico/acadêmico e político/burocrático. O critério de seleçấo dos agentes considerou ainda as discussões que estáo sendo realizadas entre a comunidade esportiva, sob a tutela do Ministério do Esporte, a fim de se (re) criar um Sistema Nacional do Esporte e Lazer. Em reunião de especialistas sobre o Sistema Nacional de Esporte e Lazer, realizada em Brasília, no mês de dezembro de 2007, e levando em conta as discussões 
realizadas na II Conferência Nacional de Esporte e Lazer, o documento final da reunião, que discutiu, entre outras coisas, qual a estrutura que compóe o Sistema Nacional de Esporte e Lazer, sua organização, agentes e competências, estabeleceu que os agentes que compóe a Estrutura Nacional do Esporte e Lazer podem ser de caráter público, privado e do terceiro setor, organizados entre: gestores do sistema, trabalhadores do sistema, agentes comunitários de esporte e lazer e usuários do sistema.

Os gestores do sistema são os agentes responsáveis pela formulação e implementação de políticas públicas de esporte e lazer, em seu trabalho no Ministério do Esporte, secretarias estaduais e municipais de esporte e lazer, conselhos de esporte e lazer, confederaçôes, ONGs, escolas, entre outros. O foco das entrevistas esteve, portanto nos gestores que têm ou tiveram responsabilidade na condução de políticas públicas no Ministério do Esporte, mas que de alguma forma se aproximam ou transitam no campo científico/ acadêmico. Para garantir o anonimato dos sujeitos de pesquisa não apresentaremos seus nomes, usando códigos para representá-los. O Comitê de Ética em Pesquisa da instituição onde a pesquisa foi realizada aprovou o projeto de pesquisa e todos os participantes assinaram o Termo de Consentimento Livre e Esclarecido.

\section{Resultados e discussão}

Segundo Alves e Pieranti 5 , a chegada de Luiz Inácio Lula da Silva à Presidência da República em 2003 foi recepcionada com entusiasmo e desconfiança. Entusiasmo refletido na aposta em mudanças, feita por parte da populaçáo na eleição de 2002. Já a desconfiança dizia respeito ao alto número de ministérios e secretarias criados pelo novo presidente, aparentemente uma forma, como se especulou, de agraciar políticos e aumentar a base de apoio ao governo 5 . Entre os novos ministérios estava o do Esporte, criado por meio da Medida Provisória n. 103 , de $1^{\circ}$ de janeiro de $2003^{6}$.

De acordo com as fontes consultadas, o processo de constituição do novo Ministério e a trajetória do próprio esporte como área do novo governo foi bastante conturbada. As propostas para o esporte e o lazer no interior do programa de governo de Lula apresentado a populaçáo no decorrer do ano de 2002 foram discutidas no interior do Setorial Nacional de Esporte e Lazer ${ }^{g}$ do PT. Todavia, durante o processo de amadurecimento do programa
O referencial teórico aqui admitido é a Teoria dos Campos de Bourdieu. Para o autor, o estudo dos contextos sociais deve estar relacionado à noçáo de campo, universos intermediários, com lógicas e dinâmicas de funcionamento próprias. Esses espaços sociais se constituem em função da presença de agentes que compartilham e perpetuam determinados "habitus" e se relacionam estrategicamente em função de objetos de disputa em comum e do acúmulo de capitalf. As disputas no interior dos campos, por sua vez, se estruturam em função da distribuição de poder. Nesse ponto, as consideraçôes de ELIAs $^{4}$ serão incorporadas à discussão. Em relação ao entendimento do poder, EliAs ${ }^{4}$ admite que os fenômenos sociais a que este conceito se refere são extremamente complexos e, portanto, de difícil compreensão. Além disso, a noção de poder é permeada por alguns "mitos", como "o poder é suspeito [...], o poder parece imoral [...], e a névoa de medo e desconfiança que se apega a este conceito transfere-se compreensivelmente para a sua utilização numa teoria científica” (p.101) mais adequada para esse entrave, segundo Elias ${ }^{4}$, seria considerar este, de modo inequívoco, como sendo uma característica estrutural de uma relação, que a penetra totalmente.

de governo de Lula, o esporte e o lazer parecem ter sido áreas consideradas menos relevantes, e por vezes deixadas de lado pela administração central do partido, como exemplificado na seguinte passagem: Em 2002, já com o Lula bastante bem colocado nas pesquisas, o partido para sistematizar tudo que havia saído dos setoriais resolve fazer um Seminário, ou um Congresso de Programa de Governo, em que os Setoriais deveriam enviar antecipadamente os documentos que haviam produzido para que fosse organizado pelo partido, pelo Diretório Nacional, um documento-síntese. E esse documento iria para esse seminário, [...] para ser discutido. Bom, nós fizemos toda essa trajetória, fomos participar em São Paulo desse encontro, e para nossa surpresa o nosso documento não foi incluído no programa de governo. [...] Ai foi uma decepçáo muito grande. Nós fizemos todo um trabalho. O próprio partido havia bancado as nossas viagens, para que a gente pudesse se deslocar para fazer o encontro em Recife, coisa e tal. E chega lá na hora, o nosso documento 
não está fazendo parte do documento geral (Gestor

A, entrevista concedida em 29 nov. 2010).

Ou seja, apesar de historicamente o esporte ter sido um tema de debate no PT, por meio do Setorial Nacional de Esporte e Lazer, quando da campanha e processo eleitoral do presidente Lula, a área acabou sendo deixada de lado, negligenciada no plano de governo do então candidato à presidência. Esse fato reflete um histórico político no Brasil que privilegia a área econômica em detrimento a área social, e que dentro da área social estabelece uma hierarquia de prioridades na qual o esporte ocupa normalmente uma das últimas posiçôes. Pensando relacionalmente, pode-se dizer que o esporte, enquanto subcampo político/burocrático, está em uma posição desprivilegiada em relação ao campo do poder, assim como outras políticas sociais. Estaria, segundo Bourdieu ${ }^{7}$, na mão esquerda do Estado. Ainda de acordo com o autor, a mão esquerda do Estado representa os agentes e estruturas das áreas de atuação relacionadas às políticas sociais; enquanto a mão direita é representada pelos ministérios relacionados à economia, como os bancos e agentes dos gabinetes ministeriais da área econômica. Essas são as instituiçôes e agentes que caracterizam as lutas principais dentro do campo político/burocrático, no qual, sob a análise do capital econômico, a mão direita é dominante e a mão esquerda dominada, constantemente lutando entre si pela dominância, sob análise do capital simbólico ${ }^{7}$. O esporte, na máo esquerda do Estado, é tido especialmente como meio de compensação das distorçôes do sistema capitalista, responsável por "exercer as funções ditas 'sociais' isto é, compensar, sem dispor de todos os meios necessários, os efeitos e carências mais intoleráveis da lógica do mercado" (p.218) ${ }^{7}$.

Vencida a eleição por Lula, o então presidente Fernando Henrique Cardoso cria o chamado "governo de transição"h , e mais uma vez os representantes do Setorial de Esporte e Lazer do PT são preteridos. "[...] O governo de transição começa a se constituir e não nos chamam [o Setorial de Esporte e Lazer]" (Gestor A, entrevista concedida em 29 nov. 2010), abrindo uma lacuna a supostos representantes do esporte no novo governo.

E várias pessoas naquele momento passam a se colocar como porta-vozes do esporte. Então existe lá o [reconhecido jornalista esportivo], diz que foi ao encontro do Lula, e que o Lula pediu a ele para fazer proposta para a área do esporte. A [ex-atleta de basquetebol] faz parte desse grupo do [reconhecido jornalista esportivo]. Ai tem um dia lá que a televisão, a própria Rede Globo vai entrevistar pessoas, e está lá o [reconhecido jornalista esportivo], com um monte de atletas do lado, de pessoas envolvidas com o esporte, e dando entrevista, falando pelo governo Lula na área do esporte (Gestor A, entrevista concedida em 29 nov. 2010).

A presença de figuras ilustres do esporte como porta-vozes no governo não foi um fato isolado ou inédito. Tal conduta foi recorrente especialmente na década de 90 no Brasil. Os ex-atletas Zico, Pelé e Bernard foram alguns dos que emprestaram seu prestígio - expressão do acúmulo de capital social, político e esportivo desses agentes - à administração pública do esporte no Brasil. O Setorial de Esporte e Lazer, não contente com essa situação e com o discurso dos supostos porta-vozes do esporte, que destoava do que havia partido do Setorial, então se articula para reivindicar junto ao PT seu espaço no governo de transição. Após algumas articulações políticas, dias depois agentes do Setorial de Esporte e Lazer são recebidos pelo governo de transição: Aí por um conjunto de articulaçóes, a gente conseguiu, através de um pessoal lá do Setorial de Recife, ter contato com uma das pessoas que fazia parte do governo de transição na área da saúde. [...] Conseguimos assim de última hora marcar, já estava quase desistindo, mas por meio dele, a gente conseguiu marcar uma conversa com o Palocci. Aí marcamos, tomamos um "chá de banco" lá algum tempo, e daí ele chama o Palocci que diz: bom, o que vocês querem? [Respondemos:] Palocci, é o velho problema, que já aconteceu lá no encontro. Existem pessoas, a gente construiu um documento que foi aprovado no encontro, e agora existe milhares de pessoas falando pelo governo, [...] a imprensa criticando, e parece que o partido está meio alheio a isso tudo. O Palocci disse: não, é verdade. Então faça o seguinte: indiquem um nome para fazer parte da transição de governo para a área do esporte. Indique, se reúne aí, e indique um nome, que eu vou bancar (Gestor A, entrevista concedida em 29 nov. 2010).

Aqui fica explícita a importância do capital político no processo do governo de transiçáo. Primeiro quando e tão somente por um conjunto de articulaçóes de agentes dotados de capital político relevante ao contexto, os agentes do Setorial de Esporte e Lazer, esses não tão dotados de tal capital, são recebidos pelo governo de transição. E depois quando um agente reconhecidamente dotado de vasto capital político junto ao presidente eleito, amparado por essa condição, assume a responsabilidade de agregar um representante do esporte ao governo de transição. 
Em reunião do Setorial em Brasília, com grande representação dos Estados, foi decidido pelo nome de Luiz Fernando Veronez para ser o coordenador do governo de transição na área de esporte e lazer. Veronez, professor da Universidade Federal de Pelotas, com trajetória na área de esporte e lazer dentro do Partido dos Trabalhadores, e presidente nacional do Setorial de Esporte e Lazer passa naquele momento a fazer parte do governo de transiçáo.

Durante o governo de transição, além do trabalho mais técnico de cada área, que levantava informações junto ao governo anterior sobre o funcionamento da máquina pública e perspectivava algumas das açóes para o início do próximo governo, houve também intensa movimentação política no sentido de definir qual seria a estrutura governamental e quem seriam os contemplados com cargos de confiança na administração pública federal.

No âmbito do esporte, segundo Bueno ${ }^{8}$, na passagem do governo FHC para o governo Lula, cogitou-se a extinção do antigo Ministério do Esporte e Turismo (MET), indo o turismo para o Ministério do Desenvolvimento e o esporte para novo Ministério da Juventude, Lazer e Esporte. Cogitouse também a criação de uma Agência Nacional para o Esporte nos moldes das demais agências, o que não inviabilizaria a existência de um ministério com pastas divididas, como já vinha ocorrendo.

Contudo, o novo governo preferiu a criação do Ministério do Esporte, atribuindo ao esporte, pela primeira vez na história do Brasil, "status" de ministério permanente, sinalizando supostamente a importância que o novo governo estava dedicando a esse campo. Essa, porém, foi uma decisão de última hora, segundo os agentes entrevistados. "[...] no dia 27 de dezembro [de 2002] [...] se define a criação do Ministério do Esporte. [...] Então, só no último, faltando [...] dois dias para a apresentaçáo do conjunto de Ministros"(Gestor A, entrevista concedida em 29 nov. 2010) que se decide pela criação de um ministério específico para o esporte. A tendência mais forte, segundo um dos gestores entrevistados, era a permanência do MET, que agregava na mesma pasta o esporte e o turismo, tendo inclusive o futuro Ministro do Turismo acertado com a equipe de transiçáo do esporte e lazer como seria a divisão de cargos do MET.

O [Ministro do Turismo] inclusive, dias antes de ser anunciada a criação do Ministério do Esporte, já estava conversando com o pessoal da transição de governo, [...] dizendo assim: olha, o negócio é o seguinte, não tem problema nenhum. Eu fico, aceito vocês dentro da mesma estrutura. Permanece o Ministério do Esporte e do Turismo, não tem problema (Gestor A, entrevista concedida em 29 nov. 2010).

O impasse pela criação ou não do Ministério do Esporte estava relacionado ao fato de que "a quem estava sendo oferecido o Ministério não queria aquele Ministério" (Gestor A, entrevista concedida em 29 nov. 2010). Ou seja, a criação do Ministério estaria condicionada ao aceite do partido que iria comandá-lo.

Quer dizer, o PCdoB, que era o partido que ainda não tinha sido contemplado no governo com nenhum ministério, e que vinha sendo um apoiador de primeiro momento do PT nas eleiçôes, e do Lula especialmente, ainda náo tinha sido acomodado. Mas o $\mathrm{PCdoB}$ nacional não queria o Ministério do Esporte. Não queria que fosse criado o Ministério do Esporte (Gestor A, entrevista concedida em 29 nov. 2010).

Ainda segundo essa fonte, corroborada por OLIVEIRA ${ }^{9}$, pesava naquele momento que o PCdoB tinha pretensóes em assumir preferencialmente o Ministério da Defesa ou ainda o Ministério da Cultura. Outros aliados do governo foram sendo acomodados nesses espaços, mas o $\mathrm{PCdoB}$ ainda resistia contra a criação do Ministério do Esporte, almejando um espaço maior ou de mais visibilidade no novo governo. Entretanto nesse momento surge uma pessoa que "já vinha falando, se manifestando, que assumiria o Ministério do Esporte. Então o pessoal [do PCdoB] de São Paulo dizendo que não queria o esporte, mas [um deputado do partido], em Brasília [...] dizendo não, eu aceito, eu quero" (Gestor $A$, entrevista concedida em 29 nov. 2010). De acordo com Bueno ${ }^{8}$, na repartição dos ministérios entre a base aliada do governo, na época composta apenas pelo próprio PT, o PCdoB, o PSB e o PL, Lula, prevendo a necessidade de negociar ministérios com outros partidos, ofereceu o Ministério do Esporte ao PCdoB. Com a intenção do PT em destinar esse espaço ao PCdoB e perante a assertiva de um importante deputado do PCdoB em assumir como ministro fica decidido a criaçáo do novo Ministério do Esporte. Ou seja, a despeito da importância constitucional do esporte ao conjunto da sociedade brasileira, o que efetivamente ocasionou a criaçáo do Ministério do Esporte, segundo as fontes consultadas, foi a acomodação política de um partido aliado.

Detentor do menor orçamento dentre todos os ministérios, foi entregue a um dos menores e mais fiéis partidos da base aliada, o PCdoB. Com 12 deputados federais e nenhum senador eleito em 2002, o partido apoiara Luiz Inácio Lula da Silva desde 
sua primeira candidatura à Presidência da República em 1989. A favor do partido no comando do novo Ministério pesaram ao menos dois argumentos, segundo Alves e Pieranti5: o primeiro era uma teórica facilidade para desenvolver seus projetos junto às instituiçóes de ensino, visto que os diretores da Uniâo Nacional dos Estudantes (UNE) pertenceram historicamente aos quadros do PCdoB, caso do ex-ministro Orlando Silva (que sucedeu Agnelo Queiroz no Ministério do Esporte), ex-presidente da UNE entre 1995 e 1997; e o segundo era a proximidade do partido com o esporte brasileiro.

Em relação ao segundo argumento, $\mathrm{o} \mathrm{PCdoB}$ tinha em seus quadros o líder do governo na Câmara dos Deputados a partir de 2003 e, depois, ministro da Coordenação Política, Presidente da Câmara dos Deputados e depois Ministro do Esporte, Aldo Rebelo. Antes disso, Aldo fora presidente da Comissão Parlamentar de Inquérito (CPI) que analisou o contrato entre a Confederação Brasileira de Futebol (CBF) e a empresa patrocinadora Nike. Já o deputado Agnelo Queiroz havia sido membro da Comissão de Educação, Cultura e Desporto da Câmara dos Deputados durante oito anosi.

Apesar da resistência em aceitá-lo num primeiro momento, após consumada a indicação do $\mathrm{PCdoB}$ para assumir o Ministério, seu presidente Renato Rabelo percebeu que a oportunidade poderia render frutos, como declarou: "No início, quando o presidente Lula propôs o Ministério do Esporte, não era exatamente o que pensava $\mathrm{o} \mathrm{PCdoB}$ porque nós não tínhamos experiência nem traquejo nessa área" (Oliveira citado por $\mathrm{BuENO}^{8}$, p.221). A inexperiência alegada não procede, haja vista os argumentos já expostos sobre a relação entre o $\mathrm{PCdoB}$ e o esporte. Aceitado o convite para dirigir o recém-criado Ministério do Esporte, o escolhido para o cargo de Ministro do Esporte foi o médico baiano e deputado pelo Distrito Federal Agnelo Queiroz, filiado ao partido desde 1985.

Definida a criação do Ministério do Esporte e seu respectivo ministro, o foco passa a ser a estruturação do Ministério e a composição da equipe de trabalho. Os representantes do Setorial de Esporte e Lazer do PT acreditavam naquele momento que "[...] o Ministério ia ter uma configuração parecida com o que tinha dentro do Ministério do Turismo" (Gestor A, entrevista concedida em 29 nov. 2010), e já almejavam dirigir a Secretaria Nacional do Esporte, braço operacional das políticas de esporte. Porém, o ministro já tinha planos para a Secretaria Nacional, que seria ocupada por um nome do PCdoB paulista, numa tentativa de diminuir a tensão interna no partido, oriunda da discordância sobre a criação do Ministério do Esporte.

Ainda com parte da estruturada herdada do antigo MET, os primeiros nomes a compor o governo no Ministério do Esporte por indicação foram: Orlando Silva, do PCdoB paulista, como Secretário Nacional do Esporte; Luiz Fernando Veronez (que um curto período de tempo foi Assessor Especial do Ministro) como Secretário Adjunto da Secretaria; Lino Castellani Filho, doutor em Educação Física, pesquisador da área de políticas públicas de esporte e lazer, e com história de militância no Partido dos Trabalhadores, inclusive no Setorial de Esporte e Lazer, como Coordenador de Políticas para a Área Social; e "o filho de um outro membro do $\mathrm{PCdoB}$, que politicamente náo tinha nada a ver, para a área tecnológica lá, que era a Rede Cenesp', a parte de alto rendimento, até se construir a estrutura nova do Ministério" (Gestor A, entrevista concedida em 29 nov. 2010). Ou seja, já em sua configuração inicial o Ministério comportava agentes oriundos de dois partidos distintos: PT e PCdoB. As indicaçóes dos agentes, por sua vez, parece ter respeitado uma lógica mista de acúmulo de capital político e capital cultural específico relacionado ao esporte.

O primeiro mês de governo seria destinado à montagem da nova estrutura ministerial, que deveria ser encaminhada ao Ministério do Planejamento até o dia 31 de janeiro de 2003. Esse processo já dava mostras de como seria a relação entre PCdoB e PT dentro do Ministério:

[...] esse tema acabou sendo o motivo de uma das primeiras crises ministeriais porque janeiro avançava e nós não tínhamos sido ainda chamados, convocados para discutir essa estrutura. E quando ficamos sabendo que ela já estava praticamente pronta, tendo sido articulada pelo Ministro e pelo seu secretário executivo [...]. E aí nós inclusive exigimos, não só nós, mas também aqueles outros setores que estavam afastados, exigimos participação nesse processo. E tivemos muito pouco tempo para intervir de fato (Gestor B, entrevista concedida em 27 out. 2010).

A estrutura do Ministério pensada pelo ministro, diferentemente do que imaginavam os representantes do PT no Ministério, era contar com uma nova estrutura ministerial, com três ou quatro secretarias nacionais. [...] queriam no mínimo três Secretarias. E uma secretaria o [ministro] insistia que fosse de inclusão social. Naquelas três manifestaçôes do esporte que estava lá na Lei Pelé, ele queria uma secretaria para cada nível. Uma secretaria para o esporte educacional, uma Secretaria de Esporte 
de Alto Rendimento, e não uma Secretaria de Esporte e Lazer, ou esporte de participação. Ele queria uma Secretaria de Inclusão Social porque ele dizia que aquilo daria maior visibilidade (Gestor A, entrevista concedida em 29 nov. 2010).

A questão de usar o nome da Secretaria Nacional como meio de dar visibilidade as açóes políticas do Ministério vem ao encontro do próprio "habitus" do campo político/burocrático. Como os cargos de gestão, especialmente nos estratos superiores da burocracia normalmente são preenchidos por critérios políticos, sendo ocupados, portanto por agentes dotados de capital político em detrimento do capital cultural técnico e específico da área, esses agentes normalmente estão imbuídos por um "habitus" essencialmente político, onde o que prevalece é o agir político, de articulação e ampliação do capital social. Essa seria a face evidentemente política do campo político/burocrático, onde o agir de um grupo de agentes visa quase que exclusivamente a acumulação de capitais político e social, com vistas normalmente à ascensão política.

Os petistas resistiram à proposta de uma Secretaria de Inclusão Social e propuseram a criação da Secretaria Nacional de Desenvolvimento do Esporte Recreativo e do Lazer, que acabou sendo aceita pelo ministro. Eles reivindicaram ainda o comando das três secretarias nacionais.

Com uma pequena estrutura administrativa, o ME contava inicialmente com uma Secretaria Executiva; com a Secretaria Nacional de Esporte Educacional (SNEED); a Secretaria Nacional de Esporte de Alto Rendimento (SNEAR); a Secretaria Nacional de Desenvolvimento do Esporte Recreativo e do Lazer (SNDEL); a Consultoria Jurídica; o Gabinete do Ministro; além de um órgão consultivo, o Conselho Nacional de Esporte, conforme FIGURA 1:

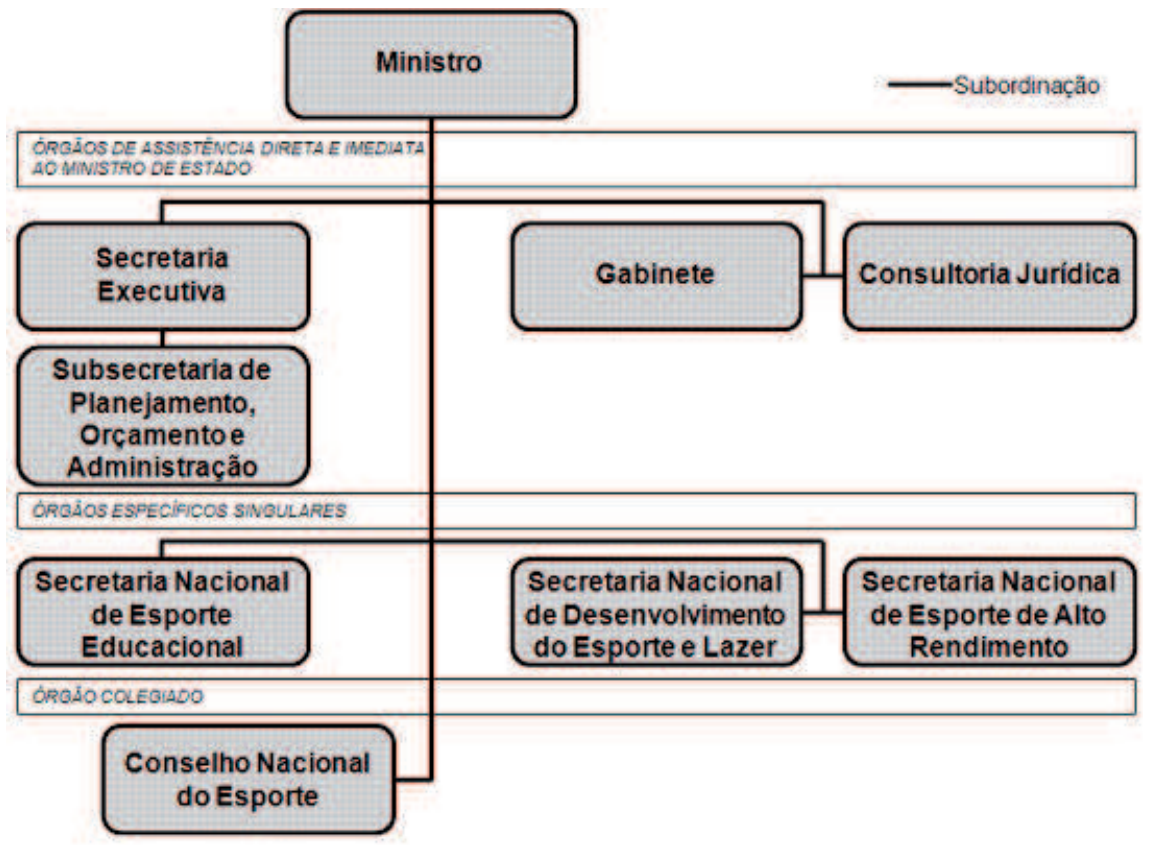

FIGURA 1 - Organograma institucional do Ministério do Esporte 2003.

Segundo um dos gestores entrevistados, a estrutura ministerial foi criada equivocadamente do ponto de vista operacional, privilegiando o gabinete do ministro e dando-lhe grande visibilidade.

[...] você percebe até hoje uma estrutura ministerial de "cabeça para baixo". A instância do Gabinete do Ministro está superdimensionada. $\mathrm{Na}$ área-fim, secretarias subdimensionadas [...], esvaziando as áreas que teriam a responsabilidade de execução propriamente dita da política (Gestor B, entrevista concedida em 27 out. 2010).
Como sustentado em outra oportunidade ${ }^{2}$, entendemos que o subcampo político/burocrático do esporte e lazer no Brasil tem historicamente se desenvolvido com base no uso do esporte para o acúmulo de capital político por parte dos agentes envolvidos na gestão pública do esporte e lazer.

Segundo Bourdieu ${ }^{11}$ (p.68), a gênese da ordem pública vem acompanhada da aparição e acumulação de um "capital público", bem como da emergência do campo burocrático, enquanto espaço de luta pelo controle desse capital e do poder correlato a ele. 
Segundo Bourdieu ${ }^{12}$, segue-se que a construção do Estado está em pé de igualdade com a construção do campo do poder, entendido como espaço de jogo, no qual os detentores de capital lutam particularmente pelo poder sobre o Estado, isto é, sobre o capital público ou estatal, que assegura o poder sobre os diferentes tipos de capital e sobre sua reprodução. Esse processo de busca da acumulação do capital público ou estatal é político e se opera por meio da política, seja ela partidária ou burocrática. O objeto de disputa do campo político/burocrático, portanto, é a acumulação do capital político, que dá acesso ao capital público ou estatal, e vice-versa, bem como a todas as vantagens decorrentes desse acúmulo.

$\mathrm{E}$ esse parece ter sido também o caso quando da estruturação do recém-criado Ministério do Esporte. Visibilidade política parecia ser uma das grandes preocupaçóes do Ministro ao criar a estrutura ministerial para o esporte, maximizando os lucros decorrentes do acúmulo de capital público ${ }^{13}$. Além disso, o Ministro, diferente do que almejava os representantes do PT, decretou que duas secretarias nacionais seriam do PCdoB e apenas uma do PT, buscando concentrar o poder nas mãos do seu partido. "Na hora da divisão da comida do prato, coube a nós [do PT] sermos servido só com a Secretaria Nacional de Desenvolvimento do Esporte e do Lazer" (Gestor A, entrevista concedida em 29 nov. 2010). Ou seja, no segundo escaláo do Ministério todos os órgãos de assistência direta ao ministro e duas das três secretarias nacionais ficariam sob o controle de agentes do PCdoB. A disputa por espaço entre o partido e o PT acabou fazendo com que a "correlaçáo de forças e poder" no Ministério do Esporte ficasse bastante favorável ao partido do Ministro, adquirindo contornos de uma relação oligárquica. Em uma situação mais antiga e oligárquica, segundo ELIAS ${ }^{4}$, o equilíbrio de poder a favor do nível mais elevado é muito desproporcional, rígido e estável. Porém, a interdependência entre os níveis impóem limitaçóes a cada jogador, mesmo no nível mais elevado.

Já no terceiro escalâo de governo, outro tensionamento ocorrido entre os agentes do PT e do PCdoB se deu com relação ao lugar do Departamento de Ciência e Tecnologia, conforme relata um dos gestores vinculados ao PT:

O Departamento de Ciência e Tecnologia num primeiro momento da estrutura pensada pelo Secretário Executivo ficaria vinculado ao altorendimento. E nós havíamos deixado claro na negociação do nosso ingresso que queríamos o

\begin{abstract}
Departamento de Ciência e Tecnologia, por conta da nossa história [no campo científico-acadêmico]. E não havia essa intenção por parte do Ministro e por parte do Secretário-Executivo, que queriam isso mais próximo deles. Se isso permanecesse com o alto-rendimento eles teriam maior controle, porque inconscientemente ou não, subliminarmente ou não, havia uma desconfiança. Nós éramos o PT e eles eram o PCdoB (Gestor B, entrevista concedida em 27 out. 2010).
\end{abstract}

Talvez o termo desconfiança náo seja o mais adequado para qualificar a relação entre os partidos na definiçáo da estrutura ministerial. Havia ali uma grande disputa por posiçóes e pelo poder no Ministério do Esporte, estrutura fundamental no subcampo político/burocrático do esporte e lazer. Com o avanço das negociaçóes o Ministro e seu Secretário Executivo decidem ceder o Departamento de Ciência e Tecnologia, que ficaria subordinado à secretaria sob comando do PT. Essa decisão, porém representou um recuo estratégico. Dias mais tarde os agentes vinculados ao PT ficam sabendo, através do Diário Oficial, que o Departamento ficaria sim com eles, mas que a Rede Cenesp passaria a ser vinculada à Secretaria Nacional de Esporte de Alto Rendimento. Esse trânsito da Rede Cenesp do Departamento de Ciência e Tecnologia para a Secretaria Nacional de Esporte de Alto Rendimento teria como motivaçáo, além da disputa interna entre PCdoB e PT no Ministério, uma disputa travada entre pesquisadores do campo da Educaçáo Física de matrizes teórico-epistemológicas distintas ${ }^{k}$.

Em síntese, o que foi exposto até aqui serve para evidenciar algumas das disputas travadas na arena política quando da concepção do $\mathrm{ME}$ e nos seus primeiros meses de existência: Ministro x PCdoB paulista; PT x PCdoB; Rede Cedes x representantes da SNDEL. Fruto de toda essa intensa atividade política se estabeleceu a estrutura do ME, conforme a FIGURA 1.

No decorrer dos anos que se seguiram, observaram-se importantes mudanças no Ministério do Esporte, que envolveram: alteraçóes do quadro de agentes diretamente vinculados ao ME; mudanças administrativas em procedimentos internos; variaçóes nas prioridades do ME no que diz respeito às manifestaçóes esportivas, entre outras. A mudança estrutural mais significativa, todavia, se efetivou através do Decreto 7.529/2011'. Por meio desse instrumento legal, a configuração do Ministério do Esporte passou a ser a descrita na FIGURA 2: 


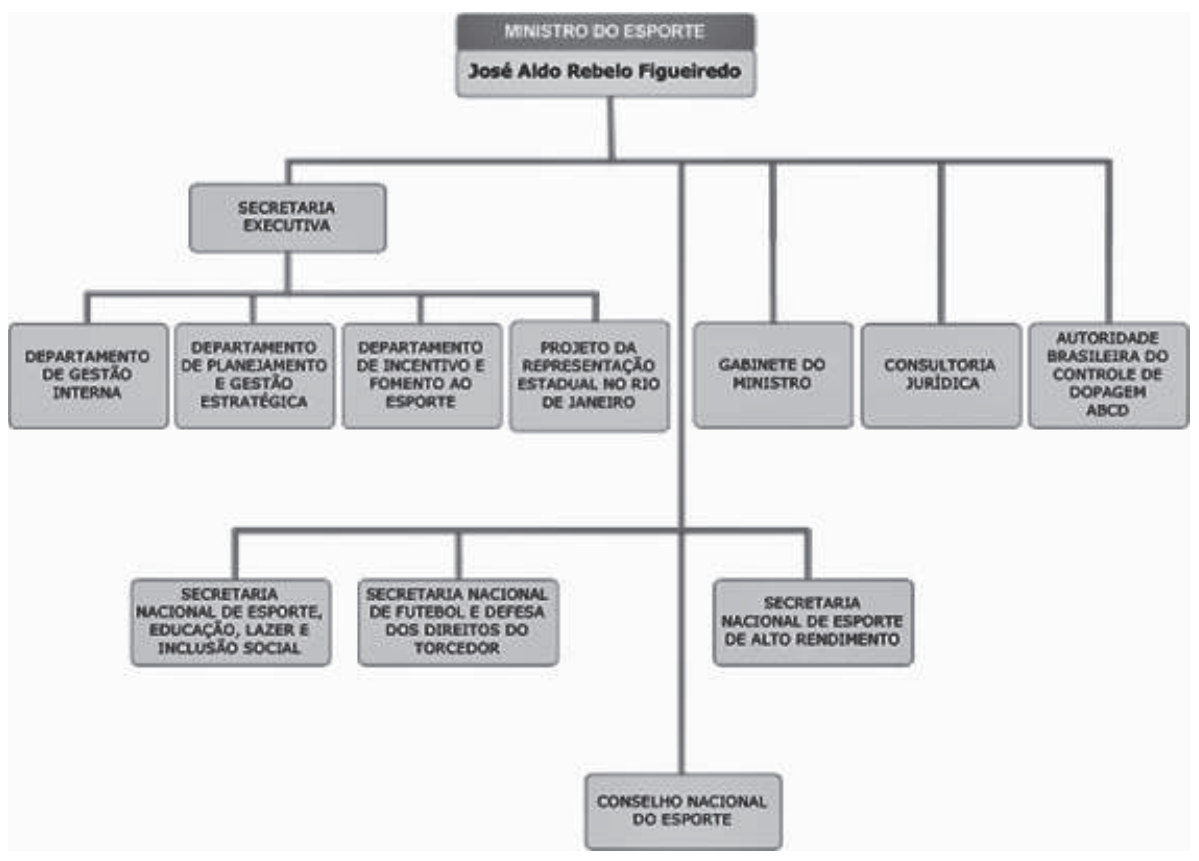

FIGURA 2 - Organograma institucional do Ministério do Esporte 2011.

Observa-se, dentre as secretarias nacionais, que se manteve a Secretaria Nacional de Esporte de Alto Rendimento, o que se mostra coerente com o histórico de distinção da manifestação esportiva de alto rendimento nas políticas públicas de esporte e lazer no Brasil. Já a Secretaria Nacional de Esporte Educacional e a Secretaria Nacional de Desenvolvimento do Esporte e Lazer foram fundidas e deram origem à Secretaria Nacional de Esporte, Educação, Lazer e Inclusão Social. Resgatando o histórico de lutas no $\mathrm{ME}$, estrutura fundamental do subcampo político/burocrático do esporte e lazer, observamos que lá na concepção do Ministério já havia um interesse explicito do partido que comandava a pasta, o PCdoB, em atrelar o esporte em sua manifestação de participação à ideia de inclusão social, o que supostamente daria mais visibilidade e apelo à pasta. Ou seja, oito anos depois, e diante de um contexto de diminuição das tensóes internas do $\mathrm{ME}$, o PCdoB consegue efetivar seu plano inicial. Tal diminuição de tensão se deu, em grande parte, pelas mudanças observadas no primeiro, segundo e terceiro escalão do $\mathrm{ME}$, que atingiu especialmente os agentes vinculados ao PT. Ocorre que ao final de todo esse processo, extinguese a Secretaria Nacional de Desenvolvimento do Esporte e Lazer, comandada pelo PT, e esta é incorporada pela Secretaria Nacional de Esporte Educacional, demonstrando claramente a correlação de forças e poder no ME, amplamente favorável ao
PCdoB, configurada de maneira oligárquica ${ }^{4}$, e a participação direta do PT no Ministério do Esporte praticamente deixa de existir.

Outras mudanças importantes observadas no $\mathrm{ME}$ em decorrência do Decreto 7.529/2011 ${ }^{1}$ foram: a valorização estratégica da Secretaria Executiva, mais próxima ao ministro, e a criação da Secretaria Nacional de Futebol e Defesa dos Direitos do Torcedor. Essa última com estreita relação à realização da Copa Fifa de Futebol masculino em 2014 no Brasil, e com a supervalorização de um esporte, o futebol, especificamente em uma manifestação do esporte, o rendimento, em detrimento a todas demais modalidades e manifestaçóes esportivas.

Enfim, o presente artigo buscou resgatar o processo de criação do Ministério do Esporte (ME) e discutir alguns aspectos conflituosos da dimensão "politics" presentes em tal "policy cycle", que podem estar relacionados à reformulação efetivada por meio do Decreto 7.529/2011 ${ }^{1}$.

Nesse sentido, e retomando as contribuiçôes de BourdiEU $^{13}$, temos que a caracterização do campo (nesse caso, falamos do Ministério do Esporte, uma estrutura componente do subcampo político/ burocrático do esporte e lazer) se dá através da definição do espaço social onde se encontram fixadas as posiçóes, e os agentes sociais movimentam-se objetivando conquistas, além de seu objeto de disputa e seus interesses específicos. Em outras palavras, o campo é definido como "o lócus onde se trava uma 
luta concorrencial entre os atores em torno de interesses específicos que caracterizam a área em questão" (p.19) ${ }^{15}$. Essas disputas, por sua vez, se estabelecem "[...] através dos alvos das lutas entre os dominantes e os pretendentes, as questóes a propósito das quais eles se enfrentam, também dependem do estado da problemática legítima” (p.64) ${ }^{16}$. As disputas em torno da conquista de espaços e estabelecimento de uma agenda de políticas públicas de esporte e lazer no interior do Ministério do Esporte estiveram pautadas, como apontamos, em disputas especialmente partidárias e políticas. Os agentes se movimentaram e atuaram no espaço social, com vistas ao acúmulo de capital e consequente estabilidade na ocupação de espaços. Todo esse intenso movimento político permeou o processo de formulação e implementação de políticas públicas de esporte e lazer durante a primeira década do século XXI e gerou, entre outros resultados, a estrutura administrativa do Ministério do Esporte, que retrata e condensa parte das tensóes experimentadas no processo, e aponta as prioridades estatais do Estado brasileiro para o esporte.

Se na estrutura administrativa do Ministério do Esporte em 2003 observávamos uma maior pluralidade de frentes de atuação do esporte, com Secretarias
Nacionais que expressavam, de maneira equivalente, as manifestaçôes esportivas reconhecidas pela legislação vigente, em 2011 observa-se uma estrutura que privilegia o esporte de rendimento, os megaeventos esportivos e o futebol em detrimentos as demais manifestaçóes. Parece ter prevalecido nesse sentido a composição oligárquica de poder no interior do $\mathrm{Mi}$ nistério do Esporte em favor de interesses políticos do PCdoB, uma vez que o histórico do desenvolvimento das políticas públicas de esporte e lazer sugere que as manifestações esportivas privilegiadas são as mais efetivas no acúmulo de capital político, que por sua vez pode reposicionar os agentes no campo político/ burocrático de maneira privilegiada.

Finalmente, cabe destacar que a pesquisa apresenta algumas limitaçóes, como o número limitado de gestores ouvidos, representantes de uma das forças envolvidas nas disputas citadas, e o salto temporal na avaliação do período de existência do Ministério. Todavia, temos clareza que as opçóes metodológicas se deram a partir do entendimento que, o que está relatado neste trabalho náo tem a pretensão de fazer o resgate fiel da história vivida naquele Ministério, apenas fazer uma das inúmeras leituras possíveis sobre algumas açôes do Ministério.

\section{Notas}

a. A principal mudança, no que se refere à estrutura organizacional do ministério diz respeito a criação da Secretaria Nacional de Esporte, Educação, Lazer e Inclusão Social em substituição as extintas Secretaria Nacional de Esporte Educacional e Secretaria Nacional de Desenvolvimento do Esporte Recreativo e do Lazer.

b. Um espaço que supóe a dissociação da posição e de seu ocupante, da função e do funcionário, do interesse público e dos interesses privados, mas que paradoxalmente funciona como um metacampo do poder, até porque a gênese da ordem pública vem acompanhada da aparição e acumulação de um "capital público" ${ }^{11}$. Cada área no interior do campo político/burocrático, por sua vez, pode ser entendida como um subcampo político/burocrático, onde as especificidades da área de atuaçáo do Estado delimitam o espaço social de atuação dos agentes a ela vinculados. Nesse caso nos referimos ao subcampo político/burocrático do esporte e lazer, constituído na década de 40 no Brasil, e que recentemente tem experimentado uma série de mudanças estruturais, especialmente a partir da criação do Ministério do Esporte.

c. Estudar a produção científica de uma área requer a investigação do espaço social (campo ou subcampo) em que esta produção está se materializando. No caso brasileiro, pode-se dizer que esse espaço social se estrutura como um campo científico/acadêmico, "lócus" de relaçôes, tendo como protagonistas agentes, que têm por delegação produzir conhecimento científico. Apesar de $\mathrm{HeY}^{17}$ entender o campo como acadêmico, e não científico, uma vez que no Brasil, tem-se mais presente a ideia de academia, com cada área do conhecimento sendo uma espécie de sociedade de caráter científico e com membros próprios, mas que tem um "ethos" comum global, admite-se aqui o campo como indissociavelmente acadêmico e científico, uma vez que a produção é científica e o meio onde é produzida é acadêmico. O campo científico/acadêmico é entâo entendido como o "lócus" onde ocorrem práticas institucionalizadas de produçáo do conhecimento, que envolve sobretudo a ideia de universidade. Cada área no interior do campo científico/acadêmico, por sua vez, pode ser entendida como um subcampo científico/acadêmico, onde as especificidades da área delimitam o espaço social de atuação dos agentes a ela vinculados, no caso as políticas públicas de esporte e lazer.

d. Ao estudar a política, devemos considerar algumas questôes de ordem teórico-metodológicas que norteiam o entendimento dos processos políticos. A primeira delas diz respeito à própria semântica da palavra política. Na língua portuguesa a 
palavra pode ter variadas conotaçôes, que no fundo se referem a diferentes etapas do processo político. Na língua inglesa, há diferenciação, através dos termos "polity", "politics" e "policy". Sumariamente, o primeiro termo designa as instituiçôes políticas; o segundo, os processos políticos; e o último os conteúdos da política. Ou seja, nesse trabalho estaremos dedicados especialmente à dimensão processual 'politics', onde se tem em vista o processo político, frequentemente de caráter conflituoso, no que diz respeito à imposição de objetivos, aos conteúdos e às decisóes de distribuição ${ }^{18}$.

e. Ciclo político ${ }^{18}$, que aqui compreende o período da criação e estruturação do Ministério do Esporte (2002/3).

f. O capital - que pode existir no estado objetivado, em forma de propriedades materiais (econômico), ou, no caso do capital cultural, no estado incorporado, e que pode ser juridicamente garantido, assim como outras formas de capital, - representa um poder sobre o campo (num dado momento) e, mais precisamente, sobre o produto acumulado do trabalho passado (em particular sobre o conjunto dos instrumentos de produção) ${ }^{19}$.As espécies de capital, a maneira dos trunfos num jogo, são os poderes que definem as probabilidades de ganho num campo determinado (a cada campo ou subcampo corresponde uma espécie de capital particular, que ocorre como poder e como coisa em jogo nesse campo), contribuindo deste modo para determinar a posição no espaço social ${ }^{19}$. Outras formas de capital (social, político, esportivo) podem ser táo ou mais importantes que o capital econômico e cultural, de acordo com o espaço social e o objeto em disputa, que se somam enquanto capital global do agente.

g. Os Setoriais são estruturas previstas no estatuto do partido integradas por filiados que atuam em determinada área específica, com o objetivo de intervir partidariamente junto aos movimentos sociais organizados. Os Setoriais podem se organizar em âmbito municipal, estadual ou nacional, mediante autorização das instâncias de direção correspondentes. O Setorial de Esporte e Lazer no PT está vinculado à Secretaria de Movimentos Populares.

h. Transição governamental é o processo que objetiva propiciar condiçôes para que o candidato eleito para o cargo de Presidente da República possa receber de seu antecessor todos os dados e informaçóes necessários à implementação do programa do novo governo, desde a data de sua posse ${ }^{20}$. O chamado governo de transiçáo começou a existir oficialmente assim que foi anunciado o novo presidente da República do Brasil, quando foram criados 51 cargos, que seriam extintos 10 dias depois da posse do novo governo. Esses funcionários ficariam na Presidência da República, mas distribuídos por diversos órgãos do Governo Federal, sendo pagos pelo Tesouro Nacional.

i. Além disso, Agnelo Queiroz teria participado da elaboração da Lei n. 10.264, que mais tarde levaria seu nome. "Sancionada pelo Presidente Fernando Henrique Cardoso em 16 de julho de 2001, a Lei n. 10.264 - conhecida como Lei Agnelo/Piva por causa do nome de dois de seus autores, o então Senador Pedro Piva (PSDB-SP) e o então Deputado Federal e ex-Ministro do Esporte Agnelo Queiroz (PCdoB-DF) - estabelece que 2\% da arrecadação bruta de todas as loterias federais do país sejam repassados ao Comitê Olímpico Brasileiro (COB) e ao Comitê Paraolímpico Brasileiro (CPB). Do total de recursos repassados, $85 \%$ são destinados ao $\mathrm{COB}$ e $15 \%$, ao $\mathrm{CPB}^{21}$.

j. A Rede Cenesp é composta por centros de desenvolvimento de pesquisa científica e tecnológica na área do esporte, treinamento e aperfeiçoamento de atletas. Formada pelas estruturas físicas e administrativas, recursos humanos e materiais existentes nas Instituiçóes de Ensino Superior, os Centros de Excelência Esportiva têm como objetivo detectar, selecionar e desenvolver talentos esportivos, especialmente nas modalidades olímpicas e paraolímpicas ${ }^{22}$.

k. A Rede Cenesp, com uma base teórico-epistemológica fundada nas ciências biológicas, e os representantes da SNDEL com base teórico-epistemológica nas ciências humanas e sociais.

\section{Abstract}

Creation and changes in the structure of the Ministry of Sport in Brazil: tensions in space definitions

This article attempts to revive the process of creating the Ministry of Sport in Brazil and discuss some aspects of conflicting politics of scale present in this policy cycle, which may be related to the reformulation effected by the recent Decree n. 7.529/2011. For this, we use the semi-structured interviews with manager agents of the Ministry of Sport. We argue in particular that the creation of the National Department of Sport, Education, Leisure and Social Inclusion is late reflection of some tensions involving agents from two different parties who have been since 2003 (year of creation of the Ministry) involved in the administration of the Ministry of Sports.

KEY WoRDS: Ministry of sports; Sports; Public policies; Policy arena. 


\section{Referências}

1. Brasil. Decreto n. 7.529 de 21 de julho de 2011. Aprova a estrutura regimental e o quadro demonstrativo dos cargos em comissão e das funçôes gratificadas do Ministério do Esporte. Diário Oficial da União, Brasília (27 jul. 2011); Sec.1:5. [citado 20 ago. 2011]. Disponível em https:/www.planalto.gov.br/ccivil_03/_ato2011-2014/2011/decreto/d7529.htm.

2. Starepravo FA. Políticas públicas de esporte e lazer no Brasil: aproximações, intersecçóes, rupturas e distanciamentos entre os subcampos político/burocrático e científico/acadêmico [tese]. Curitiba (PR): UFPR; 2011.

3. Amaral SCF, Pereira APC. Reflexões sobre a produção em políticas públicas de educação física, esporte e lazer. Rev Bras Ciênc Esporte. 2009;31:41-56.

4. Elias N. Introdução à sociologia. São Paulo: Edições 70; 2005.

5. Alves JAB, Pieranti OP. O Estado e a formulação de uma política nacional de esporte no Brasil. Rev Adm Empres. 2007;6:1-20.

6. Brasil. Medida provisória n. 103 de $1^{\text {o }}$ de janeiro de 2003 - convertida na Lei n. 10.683, de 2003. Dispóe sobre a organização da Presidência da República e dos Ministérios, e dá outras providências. Diário Oficial da União, Brasília (1 jan. 2013); Sec.1:1. [citado 30 ago. 2008]. Disponível em http://www. planalto.gov.br/ccivil03/mpv/Antigas_2003/103.htm.

7. Bourdieu P, coordenador. Miséria do mundo. 5a ed. Azevedo MSS, et al., tradutores. Petrópolis: Vozes; 2003.

8. Bueno L. Políticas públicas do esporte no Brasil: razóes para o predomínio do alto rendimento [tese]. São Paulo (SP): Escola de Administração de Empresas de São Paulo da Fundação Getúlio Vargas; 2008.

9. Oliveira ZB. O PCdoB e o ministério do Esporte. ADITAL: Notícias da América do Sul e Caribe. 9 dez. 2002. [citado 20 ago. 2008]. Disponível em: http://www.adital.org.br/site/noticia.asp? busca=\&cod=4777\&lang=PT.

10. Almeida BS. O financiamento do esporte olímpico e suas relaçóes com a política no Brasil [dissertação]. Curitiba (PR): Universidade Federal do Paraná; 2010.

11. Bourdieu P. A casa do rei à razão de Estado: um modelo da gênese do campo burocrático. In: Wacquant L, organizador. O mistério do ministério: Pierre Bourdieu e a política democrática. Rio de Janeiro: Revan; 2005. p.41-70.

12. Bourdieu P. Espaço social e espaço simbólico. In: Razóes práticas: sobre a teoria da ação. Corrêa M, tradutora. Campinas: Papirus; 2007. p.13-44.

13. Bourdieu P. Questóes de sociologia. Rio de Janeiro: Marco Zero; 1983.

14. Brasil. Ministério do Esporte. Organograma. [citado 18 mar. 2012]. Disponível em: http://www.esporte.gov.br/institucional/organograma/organograma.jsp.

15. Ortiz R. Pierre Bourdieu. São Paulo: Ática; 1994.

16. Bourdieu P. Razốes práticas: sobre a teoria da ação. Tradução: Mariza Corrêa. Campinas: Papirus, 2007.

17. Hey AP. Esboço de uma sociologia do campo acadêmico: a educação superior no Brasil. São Carlos: EdUFSCar; 2008.

18. Frey K. Políticas públicas: um debate conceitual e reflexóes referentes à prática da análise de políticas públicas no Brasil. Planej Polít Públicas. 2000;21:211-59.

19. Bourdieu P. O poder simbólico. tradução Fernando Tomaz. 7a ed. Rio de Janeiro: Bertrand Brasil; 2004.

20. Brasil. Decreto n. 4.298 de 11 de julho de 2002. Dispóe sobre a atuaçáo dos órgãos e entidades da administração pública federal durante o processo de transição governamental. Diário Oficial da União, Brasília (12 jul. 2002); Sec.1:20. [citado 30 nov. 2011]. Disponível em http://www.tce.to.gov.br/sitephp/aplic/controleInterno/ docs/decreto.pdf.

21. Comitê Olímpico Brasileiro. O que é a Lei Agnelo Piva? [citado 21 set. 2010]. Disponível em: http://www.cob.org. br/sobre_cob/agnelo_piva.asp.

22. Brasil. Ministério do Esporte. CENESP. [citado 30 ago. 2008] Disponível em: http://portal.esporte.gov.br/snear/ cenesp/default.jsp.

\section{Agradecimentos}

Os autores agradecem o apoio financeiro recebido pela CAPES/REUNI. 
Starepravo FA, et al.

ENDEREÇO

Fernando Augusto Starepravo Departamento de Educação Física Centro de Ciências da Saúde Universidade Estadual de Maringá Av. Colombo, 5790 87020-900 - Maringá - PR - BRASIL e-mail: fernando.starepravo@hotmail.com
Recebido para publicação: 14/07/2012

1a. Revisão: 18/09/2013

2a. Revisão: 17/11/2013

3a. Revisão: 27/11/2013

Aceito: 28/11/2013

228 • Rev Bras Educ Fís Esporte, (São Paulo) 2015 Abr-Jun; 29(2):217-28 